\title{
After Access: Inclusion, Development, and a More Mobile Internet
}

Johnathan Donner

Cambridge, MA: MIT Press, 2015, pp. 312, ISBN: 978-0-262-02992-6

Aided by the increasing availability of internet-enabled low-cost mobile phones, recent years have witnessed rapid growth in internet access - especially in low- and middle-income countries. As the constraint of availability vanishes, new questions emerge relating to how people engage with the (mobile) internet. This is the subject of Jonathan Donner's latest book After Access, which documents and analyses the current state of mobile internet usage around the world. His global scope, analysis of the implications of internet use for livelihoods and participation, and interest in digital divides speak to the broader development community as well as to the specific disciplines of mobile communication studies, and information and communication technologies and development (or "ICTD”).

Donner makes two main arguments. First, an increasingly mobile internet broadens the space of people's information consumption and production, while augmenting their experience of the local environment at the same time. Second, the engagement with the mobile internet is also subject to frictions that can reinforce existing differences and produce new divides in online consumption, production, and visibility. These systematic differences are explained by his "After Access" framework which takes into account the design characteristics of the mobile internet (p. 64), internet usage rather than mere access (“effective use," p. 117), and people's portfolios of digital solutions (“digital repertoires," p. 106). This framework leads us away from the notion of a single uniform (mobile) internet, which raises interesting questions about the nature and process of mobile internet diffusion. How can we think beyond binary conceptualisations of digital exclusion? What will the internet mean to the millions of new users who have only ever experienced access through a mobile phone? And what technological 
landscapes do internet users negotiate? Questions such as these are important for global technology diffusion research and can help to inform development-related topics like technology-aided public service delivery for marginalised communities.

However, After Access struggles with its analytical concepts and biased approach to digitally aided socioeconomic development. Donner's notion of "effective" internet use is particularly problematic in this respect. Despite defining it as "directionally progressive and developmental" (p. 117), his vague operationalisation of "effective use" potentially includes any kind of online engagement, which he justifies with reference to Amartya Sen's Capability Approach and Dorothea Kleine's choice framework. For example, playing online games and using online social networking sites are argued to build social and perhaps even economic capital (pp. 117-118). This might be the case for certain population sub-groups and specific uses of the internet (e.g. social networks among migrants), but it is difficult to defend generalisations about the development implications of increased internet use on the basis of specific cases as the internet has many uses, not all of which people may have reason to value from a capability perspective.

Related to the previous point, Donner's approach reflects a pro-technology bias (pp. 14-15). For example, although he lists potentially detrimental uses of the mobile internet in his discussion of socioeconomic development outcomes (e.g. p. 100), he claims that we should be hopeful "on balance" regarding the positive outcomes of digital inclusion (p. 93). Similarly, his analysis of digital divides is based on the (implicit) premise that inequalities between different groups arise because the benefits of online engagement do not materialise to the same extent for everyone, thus ignoring the distribution of disadvantage and harm relative to non-internet activities. It remains unclear how Donner's framework could address such analytical bias, given that it does not permit ex-ante consideration of specific development outcomes associated with mobile internet usage (in fairness, many lenses in the field of "ICTD" do not). 
In sum, Donner manages to present an impressive overview of recent trends, and his knowledge of the literature makes the book a valuable source of reference for development scholars interested in mobile internet research. His "After Access Lens" can also complement other frameworks that focus on digital divides. However, Donner's contribution is weakened by conceptual imprecisions, pro-technology bias, and lack of theoretical depth. These limitations reduce the usefulness of his framework to illuminate individual, social, and institutional factors of digital inclusion; other domains of socioeconomic development such as education or health; and development processes in which internet use might be inconsequential or even disadvantageous (pp. 180-183). Scholars interested in deeper sociological and theoretical engagement with mobile phone diffusion may complement their reading with Rich Ling's Taken for Grantedness (MIT Press, Cambridge, MA, 2012) and Dorothea Kleine's Technologies of Choice? (MIT Press, Cambridge, MA, 2013).

Marco J. Haenssgen (C) 2017 Nuffield Department of Medicine, University of Oxford, UK marco.haenssgen@ndm.ox.ac.uk 